\title{
Common fixed point theorems for multi-valued mappings in complex-valued metric spaces
}

\author{
Akbar Azam', Jamshaid Ahmad ${ }^{1 *}$ and Poom Kumam²
}

\section{"Correspondence:}

jamshaid_jasim@yahoo.com

'Department of Mathematics, COMSATS Institute of Information

Technology, Chack Shahzad, Islamabad, 44000, Pakistan

Full list of author information is available at the end of the article

\begin{abstract}
Azam et al. (Numer. Funct. Anal. Optim. 33(5):590-600, 2012) introduced the notion of complex-valued metric spaces and established a common fixed point result in the context of complex-valued metric spaces. In this paper, the existence of common fixed points is established for multi-valued mappings on the complex-valued metric spaces. Our results unify, generalize and complement the comparable results from the current literature.
\end{abstract}

MSC: $46 \mathrm{~S} 40 ; 47 \mathrm{H} 10 ; 54 \mathrm{H} 25$

Keywords: complex-valued metric space; multi-valued mappings; common fixed point; rational contractions

\section{Introduction}

It is a well-known fact that the mathematical results regarding fixed points of contractiontype mappings are very useful for determining the existence and uniqueness of solutions to various mathematical models. Over the last 40 years, the theory of fixed points has been developed regarding the results that are related to finding the fixed points of self and nonself nonlinear mappings in a metric space.

The study of fixed points for multi-valued contraction mappings was initiated by Nadler [1] and Markin [2]. Several authors proved fixed point results in different types of generalized metric spaces [3-17].

Azam et al. [9] introduced the concept of complex-valued metric space and obtained sufficient conditions for the existence of common fixed points of a pair of mappings satisfying a contractive-type condition. Subsequently, Rouzkard and Imdad [18] established some common fixed point theorems satisfying certain rational expressions in complexvalued metric spaces to generalize the results of [9]. In the same way, Sintunavarat and Kumam $[19,20]$ obtained common fixed point results by replacing the constant of contractive condition to control functions. Recently, Sitthikul and Saejung [21] and Klin-eam and Suanoom [22] established some fixed point results by generalizing the contractive conditions in the context of complex-valued metric spaces. Very recently, Ahmad et al. [5] obtained some new fixed point results for multi-valued mappings in the setting of complex-valued metric spaces.

The purpose of this paper is to study common fixed points of two multi-valued mappings satisfying a rational inequality without exploiting any type of commutativity con-

\section{空 Springer}

@2013 Azam et al.; licensee Springer. This is an Open Access article distributed under the terms of the Creative Commons Attribution License (http://creativecommons.org/licenses/by/2.0), which permits unrestricted use, distribution, and reproduction in any medium, provided the original work is properly cited. 
dition in the framework of a complex-valued metric space. The results presented in this paper substantially extend and strengthen the results given in $[5,9]$ for the multi-valued mappings.

\section{Preliminaries}

Let $\mathbb{C}$ be the set of complex numbers and $z_{1}, z_{2} \in \mathbb{C}$. Define a partial order $\precsim$ on $\mathbb{C}$ as follows:

$$
z_{1} \precsim z_{2} \quad \text { if and only if } \quad \operatorname{Re}\left(z_{1}\right) \leq \operatorname{Re}\left(z_{2}\right), \quad \operatorname{Im}\left(z_{1}\right) \leq \operatorname{Im}\left(z_{2}\right) .
$$

It follows that

$$
z_{1} \precsim z_{2}
$$

if one of the following conditions is satisfied:

(i) $\operatorname{Re}\left(z_{1}\right)=\operatorname{Re}\left(z_{2}\right), \operatorname{Im}\left(z_{1}\right)<\operatorname{Im}\left(z_{2}\right)$,

(ii) $\operatorname{Re}\left(z_{1}\right)<\operatorname{Re}\left(z_{2}\right), \operatorname{Im}\left(z_{1}\right)=\operatorname{Im}\left(z_{2}\right)$,

(iii) $\operatorname{Re}\left(z_{1}\right)<\operatorname{Re}\left(z_{2}\right), \operatorname{Im}\left(z_{1}\right)<\operatorname{Im}\left(z_{2}\right)$,

(iv) $\operatorname{Re}\left(z_{1}\right)=\operatorname{Re}\left(z_{2}\right), \operatorname{Im}\left(z_{1}\right)=\operatorname{Im}\left(z_{2}\right)$.

In particular, we will write $z_{1} \precsim z_{2}$ if $z_{1} \neq z_{2}$ and one of (i), (ii) and (iii) is satisfied and we will write $z_{1} \prec z_{2}$ if only (iii) is satisfied. Note that

$$
\begin{aligned}
& 0 \precsim z_{1} \precsim z_{2} \quad \Longrightarrow \quad\left|z_{1}\right|<\left|z_{2}\right|, \\
& z_{1} \preceq z_{2}, \quad z_{2} \prec z_{3} \quad \Longrightarrow \quad z_{1} \prec z_{3} .
\end{aligned}
$$

Definition 1 Let $X$ be a nonempty set. Suppose that the mapping

$$
d: X \times X \rightarrow \mathbb{C}
$$

satisfies:

1. $\quad 0 \precsim d(x, y)$ for all $x, y \in X$ and $d(x, y)=0$ if and only if $x=y$;

2. $\quad d(x, y)=d(y, x)$ for all $x, y \in X$;

3. $\quad d(x, y) \precsim d(x, z)+d(z, y)$ for all $x, y, z \in X$.

Then $d$ is called a complex-valued metric on $X$, and $(X, d)$ is called a complex-valued metric space. A point $x \in X$ is called an interior point of a set $A \subseteq X$ whenever there exists $0 \prec r \in \mathbb{C}$ such that

$$
B(x, r)=\{y \in X: d(x, y) \prec r\} \subseteq A
$$

A point $x \in X$ is called a limit point of $A$ whenever, for every $0 \prec r \in \mathbb{C}$,

$$
B(x, r) \cap(A \backslash\{x\}) \neq \phi .
$$

$A$ is called open whenever each element of $A$ is an interior point of $A$. Moreover, a subset $B \subseteq X$ is called closed whenever each limit point of $B$ belongs to $B$. The family

$$
F=\{B(x, r): x \in X, 0 \prec r\}
$$

is a sub-basis for a Hausdorff topology $\tau$ on $X$. 
Let $x_{n}$ be a sequence in $X$ and $x \in X$. If for every $c \in \mathbb{C}$ with $0 \prec c$ there is $n_{0} \in \mathbb{N}$ such that for all $n>n_{0}, d\left(x_{n}, x\right) \prec c$, then $\left\{x_{n}\right\}$ is said to be convergent, $\left\{x_{n}\right\}$ converges to $x$ and $x$ is the limit point of $\left\{x_{n}\right\}$. We denote this by $\lim _{n \rightarrow \infty} x_{n}=x$, or $x_{n} \rightarrow x$, as $n \rightarrow \infty$. If for every $c \in \mathbb{C}$ with $0 \prec c$ there is $n_{0} \in \mathbb{N}$ such that for all $n>n_{0}, d\left(x_{n}, x_{n+m}\right) \prec c$, where $m \in \mathbb{N}$, then $\left\{x_{n}\right\}$ is called a Cauchy sequence in $(X, d)$. If every Cauchy sequence is convergent in $(X, d)$, then $(X, d)$ is called a complete complex-valued metric space. We require the following lemmas.

Lemma 2 [9] Let $(X, d)$ be a complex-valued metric space and let $\left\{x_{n}\right\}$ be a sequence in $X$. Then $\left\{x_{n}\right\}$ converges to $x$ if and only if $\left|d\left(x_{n}, x\right)\right| \rightarrow 0$ as $n \rightarrow \infty$.

Lemma 3 [9] Let $(X, d)$ be a complex-valued metric space and let $\left\{x_{n}\right\}$ be a sequence in $X$. Then $\left\{x_{n}\right\}$ is a Cauchy sequence if and only if $\left|d\left(x_{n}, x_{n+m}\right)\right| \rightarrow 0$ as $n \rightarrow \infty$, where $m \in \mathbb{N}$.

\section{Main result}

Let $(X, d)$ be a complex-valued metric space.

We denote the family of nonempty, closed and bounded subsets of a complex valued metric space by $C B(X)$.

From now on, we denote $s\left(z_{1}\right)=\left\{z_{2} \in \mathbb{C}: z_{1} \preceq z_{2}\right\}$ for $z_{1} \in \mathbb{C}$, and $s(a, B)=\bigcup_{b \in B} s(d(a$, $b))=\bigcup_{b \in B}\{z \in \mathbb{C}: d(a, b) \preceq z\}$ for $a \in X$ and $B \in C B(X)$.

For $A, B \in C B(X)$, we denote

$$
s(A, B)=\left(\bigcap_{a \in A} s(a, B)\right) \cap\left(\bigcap_{b \in B} s(b, A)\right) .
$$

Remark 4 [5] Let $(X, d)$ be a complex-valued metric space. If $\mathbb{C}=R$, then $(X, d)$ is a metric space. Moreover, for $A, B \in C B(X), H(A, B)=\inf s(A, B)$ is the Hausdorff distance induced by $d$.

Definition 5 [5] Let $(X, d)$ be a complex-valued metric space. Let $T: X \rightarrow C B(X)$ be a multi-valued map. For $x \in X$ and $A \in C B(X)$, define

$$
W_{x}(A)=\{d(x, a): a \in A\}
$$

Thus, for $x, y \in X$,

$$
W_{x}(T y)=\{d(x, u): u \in T y\}
$$

Definition $6[5]$ Let $(X, d)$ be a complex-valued metric space. A subset $A$ of $X$ is called bounded from below if there exists some $z \in X$ such that $z \preceq a$ for all $a \in A$.

Definition 7 [5] Let $(X, d)$ be a complex-valued metric space. A multi-valued mapping $F: X \rightarrow 2^{\mathbb{C}}$ is called bounded from below if for each $x \in X$ there exists $z_{x} \in \mathbb{C}$ such that

$$
z_{x} \preceq u
$$

for all $u \in F x$. 
Definition 8 [5] Let $(X, d)$ be a complex-valued metric space. The multi-valued mapping $T: X \rightarrow C B(X)$ is said to have the lower bound property (l.b property) on $(X, d)$ if the for any $x \in X$, the multi-valued mapping $F_{x}: X \rightarrow 2^{\mathbb{C}}$ defined by

$$
F_{x}(y)=W_{x}(T y)
$$

is bounded from below. That is, for $x, y \in X$, there exists an element $l_{x}(T y) \in \mathbb{C}$ such that

$$
l_{x}(T y) \preceq u
$$

for all $u \in W_{x}(T y)$, where $l_{x}(T y)$ is called a lower bound of $T$ associated with $(x, y)$.

Definition 9 [5] Let $(X, d)$ be a complex-valued metric space. The multi-valued mapping $T: X \rightarrow C B(X)$ is said to have the greatest lower bound property (g.l.b property) on $(X, d)$ if a greatest lower bound of $W_{x}(T y)$ exists in $\mathbb{C}$ for all $x, y \in X$. We denote $d(x, T y)$ by the g.l.b of $W_{x}(T y)$. That is,

$$
d(x, T y)=\inf \{d(x, u): u \in T y\} .
$$

Theorem 10 Let $(X, d)$ be a complete complex-valued metric space and let $S, T: X \rightarrow$ $C B(X)$ be multi-valued mappings with g.l.b property such that

$$
a d(x, T y)+b d(y, S x)+c \frac{d(x, T y) d(y, S x)}{1+d(x, y)} \in s(S x, T y)
$$

for all $x, y \in X$ and $a+b+c<1$. Then $S$ and $T$ have a common fixed point.

Proof Let $x_{0}$ be an arbitrary point in $X$ and $x_{1} \in S x_{0}$. From (3.1), we have

$$
a d\left(x_{0}, T x_{1}\right)+b d\left(x_{1}, S x_{0}\right)+c \frac{d\left(x_{0}, T x_{1}\right) d\left(x_{1}, S x_{0}\right)}{1+d\left(x_{0}, x_{1}\right)} \in s\left(S x_{0}, T x_{1}\right) .
$$

This implies that

$$
a d\left(x_{0}, T x_{1}\right)+b d\left(x_{1}, S x_{0}\right)+c \frac{d\left(x_{0}, T x_{1}\right) d\left(x_{1}, S x_{0}\right)}{1+d\left(x_{0}, x_{1}\right)} \in\left(\bigcap_{x \in S x_{0}} s\left(x, T x_{1}\right)\right)
$$

and

$$
a d\left(x_{0}, T x_{1}\right)+b d\left(x_{1}, S x_{0}\right)+c \frac{d\left(x_{0}, T x_{1}\right) d\left(x_{1}, S x_{0}\right)}{1+d\left(x_{0}, x_{1}\right)} \in s\left(x, T x_{1}\right) \quad \text { for all } x \in S x_{0} .
$$

Since $x_{1} \in S x_{0}$, so we have

$$
a d\left(x_{0}, T x_{1}\right)+b d\left(x_{1}, S x_{0}\right)+c \frac{d\left(x_{0}, T x_{1}\right) d\left(x_{1}, S x_{0}\right)}{1+d\left(x_{0}, x_{1}\right)} \in s\left(x_{1}, T x_{1}\right)
$$

and

$$
a d\left(x_{0}, T x_{1}\right)+b d\left(x_{1}, S x_{0}\right)+c \frac{d\left(x_{0}, T x_{1}\right) d\left(x_{1}, S x_{0}\right)}{1+d\left(x_{0}, x_{1}\right)} \in s\left(x_{1}, T x_{1}\right)=\bigcup_{x \in T x_{1}} s\left(d\left(x_{1}, x\right)\right) .
$$


So there exists some $x_{2} \in T x_{1}$ such that

$$
a d\left(x_{0}, T x_{1}\right)+b d\left(x_{1}, S x_{0}\right)+c \frac{d\left(x_{0}, T x_{1}\right) d\left(x_{1}, S x_{0}\right)}{1+d\left(x_{0}, x_{1}\right)} \in s\left(d\left(x_{1}, x_{2}\right)\right) .
$$

That is,

$$
d\left(x_{1}, x_{2}\right) \preceq a d\left(x_{0}, T x_{1}\right)+b d\left(x_{1}, S x_{0}\right)+c \frac{d\left(x_{0}, T x_{1}\right) d\left(x_{1}, S x_{0}\right)}{1+d\left(x_{0}, x_{1}\right)} .
$$

By using the greatest lower bound property (g.l.b property) of $S$ and $T$, we get

$$
d\left(x_{1}, x_{2}\right) \preceq a d\left(x_{0}, x_{2}\right)+b d\left(x_{1}, x_{1}\right)+c \frac{d\left(x_{0}, x_{2}\right) d\left(x_{1}, x_{1}\right)}{1+d\left(x_{0}, x_{1}\right)},
$$

which implies that

$$
\left|d\left(x_{1}, x_{2}\right)\right| \leq a\left|d\left(x_{0}, x_{2}\right)\right|+b\left|d\left(x_{1}, x_{1}\right)\right|+c \frac{\left|d\left(x_{0}, x_{2}\right)\right|\left|d\left(x_{1}, x_{1}\right)\right|}{\left|1+d\left(x_{0}, x_{1}\right)\right|} .
$$

So, we have

$$
\left|d\left(x_{1}, x_{2}\right)\right| \leq a\left|d\left(x_{0}, x_{1}\right)\right|+a\left|d\left(x_{1}, x_{2}\right)\right| .
$$

Thus, we have

$$
\left|d\left(x_{1}, x_{2}\right)\right| \leq\left(\frac{a}{1-a}\right)\left|d\left(x_{0}, x_{1}\right)\right|
$$

Since $a, b, c$ are nonnegative reals and $a+b+c<1$, so $\rho=\frac{a}{1-a}<1$, so we have

$$
\left|d\left(x_{1}, x_{2}\right)\right| \leq \rho\left|d\left(x_{0}, x_{1}\right)\right|
$$

Inductively, we can construct a sequence $\left\{x_{n}\right\}$ in $X$ such that for $n=0,1,2, \ldots$,

$$
\left|d\left(x_{n}, x_{n+1}\right)\right| \leq \rho^{n}\left|d\left(x_{0}, x_{1}\right)\right|
$$

with $\rho=\frac{a}{1-a}<1, x_{2 n+1} \in S x_{2 n}$ and $x_{2 n+2} \in T x_{2 n+1}$. Now, for $m>n$, we get

$$
\begin{aligned}
\left|d\left(x_{n}, x_{m}\right)\right| & \leq\left|d\left(x_{n}, x_{n+1}\right)\right|+\left|d\left(x_{n+1}, x_{n+2}\right)\right|+\cdots+\left|d\left(x_{m-1}, x_{m}\right)\right| \\
& \leq\left[\rho^{n}+\rho^{n+1}+\cdots+\rho^{m-1}\right]\left|d\left(x_{0}, x_{1}\right)\right| \\
& \leq\left[\frac{\rho^{n}}{1-\rho}\right]\left|d\left(x_{0}, x_{1}\right)\right|,
\end{aligned}
$$

and so

$$
\left|d\left(x_{n}, x_{m}\right)\right| \leq \frac{\rho^{n}}{1-\rho}\left|d\left(x_{0}, x_{1}\right)\right| \rightarrow 0 \quad \text { as } m, n \rightarrow \infty
$$


This implies that $\left\{x_{n}\right\}$ is a Cauchy sequence in $X$. Since $X$ is complete, there exists $v \in X$ such that $x_{n} \rightarrow v$ as $n \rightarrow \infty$. We now show that $v \in T v$ and $v \in S v$. From (3.1), we get

$$
a d\left(x_{2 n}, T v\right)+b d\left(v, S x_{2 n}\right)+c \frac{d\left(x_{2 n}, T v\right) d\left(v, S x_{2 n}\right)}{1+d\left(x_{2 n}, v\right)} \in s\left(S x_{2 n}, T v\right) .
$$

This implies that

$$
a d\left(x_{2 n}, T v\right)+b d\left(v, S x_{2 n}\right)+c \frac{d\left(x_{2 n}, T v\right) d\left(v, S x_{2 n}\right)}{1+d\left(x_{2 n}, v\right)} \in\left(\bigcap_{x \in S x_{2 n}} s(x, T v)\right)
$$

and we have

$$
a d\left(x_{2 n}, T v\right)+b d\left(v, S x_{2 n}\right)+c \frac{d\left(x_{2 n}, T v\right) d\left(v, S x_{2 n}\right)}{1+d\left(x_{2 n}, v\right)} \in s(x, T v) \quad \text { for all } x \in S x_{2 n} .
$$

Since $x_{2 n+1} \in S x_{2 n}$, so we have

$$
a d\left(x_{2 n}, T v\right)+b d\left(v, S x_{2 n}\right)+c \frac{d\left(x_{2 n}, T v\right) d\left(v, S x_{2 n}\right)}{1+d\left(x_{2 n}, v\right)} \in s\left(x_{2 n+1}, T v\right) .
$$

By definition, we obtain

$$
a d\left(x_{2 n}, T v\right)+b d\left(v, S x_{2 n}\right)+c \frac{d\left(x_{2 n}, T v\right) d\left(v, S x_{2 n}\right)}{1+d\left(x_{2 n}, v\right)} \in s\left(x_{2 n+1}, T v\right)=\bigcup_{u^{\prime} \in T u} s\left(d\left(x_{2 n+1}, u^{\prime}\right)\right) .
$$

There exists some $v_{n} \in T v$ such that

$$
a d\left(x_{2 n}, T v\right)+b d\left(v, S x_{2 n}\right)+c \frac{d\left(x_{2 n}, T v\right) d\left(v, S x_{2 n}\right)}{1+d\left(x_{2 n}, v\right)} \in s\left(x_{2 n+1}, T v\right) \in s\left(d\left(x_{2 n+1}, v_{n}\right)\right),
$$

that is,

$$
d\left(x_{2 n+1}, v_{n}\right) \preceq a d\left(x_{2 n}, T v\right)+b d\left(v, S x_{2 n}\right)+c \frac{d\left(x_{2 n}, T v\right) d\left(v, S x_{2 n}\right)}{1+d\left(x_{2 n}, v\right)} .
$$

By using the greatest lower bound property (g.l.b property) of $S$ and $T$, we have

$$
d\left(x_{2 n+1}, v_{n}\right) \preceq a d\left(x_{2 n}, v_{n}\right)+b d\left(v, x_{2 n+1}\right)+c \frac{d\left(x_{2 n}, v_{n}\right) d\left(v, x_{2 n+1}\right)}{1+d\left(x_{2 n}, v\right)} .
$$

Now, by using the triangular inequality, we get

$$
d\left(x_{2 n+1}, v_{n}\right) \preceq a d\left(x_{2 n}, x_{2 n+1}\right)+a d\left(x_{2 n+1}, v_{n}\right)+b d\left(v, x_{2 n+1}\right)+c \frac{d\left(x_{2 n}, v_{n}\right) d\left(v, x_{2 n+1}\right)}{1+d\left(x_{2 n}, v\right)},
$$

and it follows that

$$
d\left(x_{2 n+1}, v_{n}\right) \preceq \frac{a}{1-a} d\left(x_{2 n}, x_{2 n+1}\right)+\frac{b}{1-a} d\left(v, x_{2 n+1}\right)+\frac{c}{1-a} \frac{d\left(x_{2 n}, v_{n}\right) d\left(v, x_{2 n+1}\right)}{1+d\left(x_{2 n}, v\right)} .
$$


By using again the triangular inequality, we get

$$
\begin{aligned}
d\left(v, v_{n}\right) \preceq & d\left(v, x_{2 n+1}\right)+d\left(x_{2 n+1}, v_{n}\right) \\
\preceq & d\left(v, x_{2 n+1}\right)+\frac{a}{1-a} d\left(x_{2 n}, x_{2 n+1}\right)+\frac{b}{1-a} d\left(v, x_{2 n+1}\right) \\
& +\frac{c}{1-a} \frac{d\left(x_{2 n}, v_{n}\right) d\left(v, x_{2 n+1}\right)}{1+d\left(x_{2 n}, v\right)}
\end{aligned}
$$

it follows that

$$
\begin{aligned}
\left|d\left(v, v_{n}\right)\right| \leq & \left|d\left(v, x_{2 n+1}\right)\right|+\frac{a}{1-a}\left|d\left(x_{2 n}, x_{2 n+1}\right)\right|+\frac{b}{1-a}\left|d\left(v, x_{2 n+1}\right)\right| \\
& +\frac{c}{1-a} \frac{\left|d\left(x_{2 n}, v_{n}\right)\right|\left|d\left(v, x_{2 n+1}\right)\right|}{\left|1+d\left(x_{2 n}, v\right)\right|} .
\end{aligned}
$$

By letting $n \rightarrow \infty$ in the above inequality, we get $\left|d\left(v, v_{n}\right)\right| \rightarrow 0$ as $n \rightarrow \infty$. By Lemma 2 [9], we have $v_{n} \rightarrow v$ as $n \rightarrow \infty$. Since $T v$ is closed, so $v \in T v$. Similarly, it follows that $v \in S \nu$. Thus $S$ and $T$ have a common fixed point.

Corollary 11 Let $(X, d)$ be a complete complex-valued metric space and let $S, T: X \rightarrow$ $C B(X)$ be multi-valued mappings with g.l.b property such that

$$
\alpha(d(x, T y)+d(y, S x)) \in s(S x, T y)
$$

for all $x, y \in X$ and $0 \leq \alpha<1$. Then $S$ and $T$ have a common fixed point.

Proof By taking $a=b$ and $c=0$ in Theorem 10.

Corollary 12 Let $(X, d)$ be a complete complex-valued metric space and let $T: X \rightarrow C B(X)$ be a multi-valued mapping with g.l.b property such that

$$
a d(x, T y)+b d(y, T x)+c \frac{d(x, T y) d(y, T x)}{1+d(x, y)} \in s(T x, T y)
$$

for all $x, y \in X$ and $a+b+c<1$. Then $T$ has a fixed point.

Proof By taking $S=T$ in Theorem 10 .

Now we obtain a common fixed point result discussed by Khan [23] in the setting of complex-valued metric spaces.

Theorem 13 Let $(X, d)$ be a complete complex-valued metric space and let $S, T: X \rightarrow$ $C B(X)$ be multi-valued mappings with g.l.b property such that

$$
\alpha \frac{[d(x, S x) d(x, T y)+d(y, T y) d(y, S x)]}{d(x, T y)+d(y, S x)} \in s(S x, T y)
$$

for all $x, y \in X$ and $0 \leq \alpha<1$. Then $S$ and $T$ have a common fixed point. 
Proof Let $x_{0} \in X$ and $x_{1} \in S x_{0}$. From (3.4), we get

$$
\frac{a\left[d\left(x_{0}, S x_{0}\right) d\left(x_{0}, T x_{1}\right)+d\left(x_{1}, T x_{1}\right) d\left(x_{1}, S x_{0}\right)\right]}{d\left(x_{0}, T x_{1}\right)+d\left(x_{1}, S x_{0}\right)} \in s\left(S x_{0}, T x_{1}\right) .
$$

This implies that

$$
\frac{a\left[d\left(x_{0}, S x_{0}\right) d\left(x_{0}, T x_{1}\right)+d\left(x_{1}, T x_{1}\right) d\left(x_{1}, S x_{0}\right)\right]}{d\left(x_{0}, T x_{1}\right)+d\left(x_{1}, S x_{0}\right)} \in\left(\bigcap_{x \in S x_{0}} s\left(x, T x_{1}\right)\right),
$$

that is,

$$
\frac{a\left[d\left(x_{0}, S x_{0}\right) d\left(x_{0}, T x_{1}\right)+d\left(x_{1}, T x_{1}\right) d\left(x_{1}, S x_{0}\right)\right]}{d\left(x_{0}, T x_{1}\right)+d\left(x_{1}, S x_{0}\right)} \in s\left(x, T x_{1}\right) \text { for all } x \in S x_{0} .
$$

Since $x_{1} \in S x_{0}$, so we have

$$
\begin{aligned}
& \frac{a\left[d\left(x_{0}, S x_{0}\right) d\left(x_{0}, T x_{1}\right)+d\left(x_{1}, T x_{1}\right) d\left(x_{1}, S x_{0}\right)\right]}{d\left(x_{0}, T x_{1}\right)+d\left(x_{1}, S x_{0}\right)} \in s\left(x_{1}, T x_{1}\right), \\
& \frac{a\left[d\left(x_{0}, S x_{0}\right) d\left(x_{0}, T x_{1}\right)+d\left(x_{1}, T x_{1}\right) d\left(x_{1}, S x_{0}\right)\right]}{d\left(x_{0}, T x_{1}\right)+d\left(x_{1}, S x_{0}\right)} \in s\left(x_{1}, T x_{1}\right)=\bigcup_{x \in T x_{1}} s\left(d\left(x_{1}, x\right)\right) .
\end{aligned}
$$

So there exists some $x_{2} \in T x_{1}$ such that

$$
\frac{a\left[d\left(x_{0}, S x_{0}\right) d\left(x_{0}, T x_{1}\right)+d\left(x_{1}, T x_{1}\right) d\left(x_{1}, S x_{0}\right)\right]}{d\left(x_{0}, T x_{1}\right)+d\left(x_{1}, S x_{0}\right)} \in s\left(d\left(x_{1}, x_{2}\right)\right) .
$$

That is,

$$
d\left(x_{1}, x_{2}\right) \preceq \frac{a\left[d\left(x_{0}, S x_{0}\right) d\left(x_{0}, T x_{1}\right)+d\left(x_{1}, T x_{1}\right) d\left(x_{1}, S x_{0}\right)\right]}{d\left(x_{0}, T x_{1}\right)+d\left(x_{1}, S x_{0}\right)} .
$$

By using the greatest lower bound property (g.l.b property) of $S$ and $T$, we get

$$
d\left(x_{1}, x_{2}\right) \preceq a \frac{d\left(x_{0}, x_{1}\right) d\left(x_{0}, x_{2}\right)+d\left(x_{1}, x_{2}\right) d\left(x_{1}, x_{1}\right)}{d\left(x_{0}, x_{2}\right)+d\left(x_{1}, x_{1}\right)},
$$

which implies that

$$
\begin{aligned}
d\left(x_{1}, x_{2}\right) & \leq a \frac{\left|d\left(x_{0}, x_{1}\right)\right|\left|d\left(x_{0}, x_{2}\right)\right|}{\left|d\left(x_{0}, x_{2}\right)\right|} \\
& =a\left|d\left(x_{0}, x_{1}\right)\right| .
\end{aligned}
$$

Inductively, we can construct a sequence $\left\{x_{n}\right\}$ in $X$ such that for $n=0,1,2 \ldots,\left|d\left(x_{n}, x_{n+1}\right)\right| \leq$ $a^{n}\left|d\left(x_{0,} x_{1}\right)\right|$ with $a<1, x_{2 n+1} \in S x_{2 n}$ and $x_{2 n+2} \in T x_{2 n+1}$. Now, for $m>n$, we get

$$
\begin{aligned}
\left|d\left(x_{n}, x_{m}\right)\right| & \leq\left|d\left(x_{n}, x_{n+1}\right)\right|+\left|d\left(x_{n+1}, x_{n+2}\right)\right|+\cdots+\left|d\left(x_{m-1}, x_{m}\right)\right| \\
& \leq\left[a^{n}+a^{n+1}+\cdots+a^{m-1}\right]\left|d\left(x_{0}, x_{1}\right)\right| \\
& \leq\left[\frac{a^{n}}{1-a}\right]\left|d\left(x_{0}, x_{1}\right)\right|
\end{aligned}
$$


and so

$$
\left|d\left(x_{n}, x_{m}\right)\right| \leq \frac{a^{n}}{1-a}\left|d\left(x_{0}, x_{1}\right)\right| \rightarrow 0 \quad \text { as } m, n \rightarrow \infty .
$$

This implies that $\left\{x_{n}\right\}$ is a Cauchy sequence in $X$. Since $X$ is complete, so there exists $v \in X$ such that $x_{n} \rightarrow v$ as $n \rightarrow \infty$. We now show that $v \in T v$ and $v \in S v$. From (3.4), we have

$$
\frac{a\left[d\left(x_{2 n}, S x_{2 n}\right) d\left(x_{2 n}, T v\right)+d(v, T v) d\left(v, S x_{2 n}\right)\right]}{d\left(x_{2 n}, T v\right)+d\left(v, S x_{2 n}\right)} \in s\left(S x_{2 n}, T v\right) .
$$

This implies that

$$
\frac{a\left[d\left(x_{2 n}, S x_{2 n}\right) d\left(x_{2 n}, T v\right)+d(v, T v) d\left(v, S x_{2 n}\right)\right]}{d\left(x_{2 n}, T v\right)+d\left(v, S x_{2 n}\right)} \in\left(\bigcap_{x \in S x_{2 n}} s(x, T v)\right),
$$

and so

$$
\frac{a\left[d\left(x_{2 n}, S x_{2 n}\right) d\left(x_{2 n}, T v\right)+d(v, T v) d\left(v, S x_{2 n}\right)\right]}{d\left(x_{2 n}, T v\right)+d\left(v, S x_{2 n}\right)} \in s(x, T v) \quad \text { for all } x \in S x_{2 n} .
$$

Since $x_{2 n+1} \in S x_{2 n}$, so we have

$$
\frac{a\left[d\left(x_{2 n}, S x_{2 n}\right) d\left(x_{2 n}, T v\right)+d(v, T v) d\left(v, S x_{2 n}\right)\right]}{d\left(x_{2 n}, T v\right)+d\left(v, S x_{2 n}\right)} \in s\left(x_{2 n+1}, T v\right) .
$$

By definition

$$
\frac{a\left[d\left(x_{2 n}, S x_{2 n}\right) d\left(x_{2 n}, T v\right)+d(v, T v) d\left(v, S x_{2 n}\right)\right]}{d\left(x_{2 n}, T v\right)+d\left(v, S x_{2 n}\right)} \in s\left(x_{2 n+1}, T v\right)=\bigcup_{u^{\prime} \in T u} s\left(d\left(x_{2 n+1}, u^{\prime}\right)\right) .
$$

There exists some $v_{n} \in T v$ such that

$$
\frac{a\left[d\left(x_{2 n}, S x_{2 n}\right) d\left(x_{2 n}, T v\right)+d(v, T v) d\left(v, S x_{2 n}\right)\right]}{d\left(x_{2 n}, T v\right)+d\left(v, S x_{2 n}\right)} \in s\left(x_{2 n+1}, T v\right) \in s\left(d\left(x_{2 n+1}, v_{n}\right)\right),
$$

that is,

$$
d\left(x_{2 n+1}, v_{n}\right) \preceq \frac{a\left[d\left(x_{2 n}, S x_{2 n}\right) d\left(x_{2 n}, T v\right)+d(v, T v) d\left(v, S x_{2 n}\right)\right]}{d\left(x_{2 n}, T v\right)+d\left(v, S x_{2 n}\right)} .
$$

By using the greatest lower bound property (g.l.b property) of $S$ and $T$, we get

$$
d\left(x_{2 n+1}, v_{n}\right) \preceq \frac{a\left[d\left(x_{2 n}, x_{2 n+1}\right) d\left(x_{2 n}, v_{n}\right)+d\left(v, v_{n}\right) d\left(v, x_{2 n+1}\right)\right]}{d\left(x_{2 n}, v_{n}\right)+d\left(v, x_{2 n+1}\right)} .
$$

By using again the triangular inequality, we get

$$
d\left(\nu, v_{n}\right) \preceq d\left(v, x_{2 n+1}\right)+d\left(x_{2 n+1}, v_{n}\right) .
$$

Then we have

$$
d\left(v, v_{n}\right) \preceq d\left(v, x_{2 n+1}\right)+\frac{a\left[d\left(x_{2 n}, x_{2 n+1}\right) d\left(x_{2 n}, v_{n}\right)+d\left(v, v_{n}\right) d\left(v, x_{2 n+1}\right)\right]}{d\left(x_{2 n}, v_{n}\right)+d\left(v, x_{2 n+1}\right)},
$$


and we obtain

$$
\left|d\left(v, v_{n}\right)\right| \leq\left|d\left(v, x_{2 n+1}\right)\right|+\frac{a\left[\left|d\left(x_{2 n}, x_{2 n+1}\right)\right|\left|d\left(x_{2 n}, v_{n}\right)\right|+\left|d\left(v, v_{n}\right)\right|\left|d\left(v, x_{2 n+1}\right)\right|\right]}{\left|d\left(x_{2 n}, v_{n}\right)\right|+\left|d\left(v, x_{2 n+1}\right)\right|} .
$$

By letting $n \rightarrow \infty$ in the above inequality, we get $\left|d\left(v, v_{n}\right)\right| \rightarrow 0$ as $n \rightarrow \infty$. By Lemma 2 [9], we have $v_{n} \rightarrow v$ as $n \rightarrow \infty$. Since $T v$ is closed, so $v \in T v$. Similarly, it follows that $v \in S v$. Thus $S$ and $T$ have a common fixed point.

Corollary 14 Let $(X, d)$ be a complete complex-valued metric space and let $T: X \rightarrow C B(X)$ be a multi-valued mapping with g.l.b property such that

$$
\alpha \frac{[d(x, T x) d(x, T y)+d(y, T y) d(y, T x)]}{d(x, T y)+d(y, T x)} \in s(T x, T y)
$$

for all $x, y \in X$ and $0 \leq \alpha<1$. Then $T$ has a fixed point.

Proof By setting $S=T$ in Theorem 13 .

Now we give an example which satisfies our main result.

Example 15 Let $X=[0,1]$. Define $d: X \times X \rightarrow \mathbb{C}$ as follows:

$$
d(x, y)=|x-y| e^{i \theta},
$$

where $\theta=\tan ^{-1}\left|\frac{y}{x}\right|$. Then $(X, d)$ is a complex-valued metric space. Consider the mappings $S, T: X \rightarrow C B(X)$ such that

$$
S x=\left\{t \in X: 0 \leq t \leq \frac{x}{5}\right\}
$$

and

$$
T x=\left\{t \in X: 0 \leq t \leq \frac{x}{3}\right\}
$$

for all $x, y \in X$. The contractive condition of the main theorem is trivial for the case when $x=y=0$. Suppose, without any loss of generality, that all $x, y$ are nonzero and $x<y$. Then

$$
\begin{aligned}
& d(y, S x)=\left|y-\frac{x}{5}\right| e^{i \theta}, \\
& d(x, T y)= \begin{cases}0 & \text { if } 0 \leq x \leq \frac{y}{3}, \\
\left|x-\frac{y}{3}\right| e^{i \theta} & \text { if } x>\frac{y}{3},\end{cases}
\end{aligned}
$$

and

$$
s(S x, T y)=s\left(\left|\frac{x}{5}-\frac{y}{3}\right| e^{i \theta}\right) .
$$


Clearly, for any value of $a$ and $c$ and $b=\frac{1}{3}$, we have

$$
d(y, S x)=\left|y-\frac{x}{5}\right| e^{i \theta} \succ \frac{1}{3}\left|y-\frac{x}{5}\right| e^{i \theta} \succ\left|\frac{y}{3}-\frac{x}{5}\right| e^{i \theta}=s(S x, T y) .
$$

Thus

$$
a d(x, T y)+b d(y, S x)+c \frac{d(x, T y) d(y, S x)}{1+d(x, y)} \in s(S x, T y) .
$$

Hence all the conditions of Theorem 10 are satisfied and 0 is a common fixed point of $S$ and $T$.

\section{Conclusion}

In this paper, we have established common fixed point results for Chatterjea-type contractive mappings in the context of complex-valued metric spaces. Our results may be the motivation for other authors to extend and improve these results to be suitable tools for their applications.

\section{Competing interests}

The authors declare that they have no competing interests.

\section{Authors' contributions}

JA derived all results communicating with AA and PK. All authors read and approved the final manuscript.

\section{Author details}

${ }^{1}$ Department of Mathematics, COMSATS Institute of Information Technology, Chack Shahzad, Islamabad, 44000, Pakistan. ${ }^{2}$ Department of Mathematics, Faculty of Science, King Mongkut's University of Technology Thonburi (KMUTT), Bangkok, 10140, Thailand.

\section{Received: 26 July 2013 Accepted: 14 November 2013 Published: 11 Dec 2013}

\section{References}

1. Nadler, SB Jr.: Multi-valued contraction mappings. Pac. J. Math. 30, 475-478 (1969)

2. Markin, JT: Continuous dependence of fixed point sets. Proc. Am. Math. Soc. 38, 545-547 (1973)

3. Abbas, M, Arshad, M, Azam, A: Fixed points of asymptotically regular mappings in complex-valued metric spaces. Georgian Math. J. 20, 213-221 (2013). doi:10.1515/gmj-2013-0013

4. Abbas, M, Fisher, B, Nazir, T: Well-posedness and periodic point property of mappings satisfying a rational inequality in an ordered complex-valued metric spaces. Numer. Funct. Anal. Optim. 32, 243-253 (2011)

5. Ahmad, J, Klin-eam, C, Azam, A: Common fixed points for multi-valued mappings in complex-valued metric spaces with applications. Abstr. Appl. Anal. 2013, Article ID 854965 (2013)

6. Arshad, M, Ahmad, J: On multivalued contractions in cone metric spaces without normality. Sci. World J. 2013, Article ID 481601 (2013)

7. Arshad, M, Azam, A, Vetro, P: Some common fixed point results in cone metric spaces. Fixed Point Theory Appl. 2009, Article ID 493965 (2009)

8. Arshad, M, Karapinar, E, Ahmad, J: Some unique fixed point theorem for rational contractions in partially ordered metric spaces. J. Inequal. Appl. 2013, Article ID 248 (2013). doi:10.1186/1029-242X-2013-248

9. Azam, A, Fisher, B, Khan, M: Corrigendum: 'Common fixed point theorems in complex valued metric spaces'. Numer. Funct. Anal. Optim. 33(5), 590-600 (2012)

10. Azam, A, Arshad, M: Common fixed points of generalized contractive maps in cone metric spaces. Bull. Iran. Math Soc. 35(2), 255-264 (2009)

11. Cho, SH, Bae, JS: Fixed point theorems for multivalued maps in cone metric spaces. Fixed Point Theory and Applications 2011, Article ID 87 (2011)

12. Huang, LG, Zhang, X: Cone metric spaces and fixed point theorems of contractive mappings. J. Math. Anal. Appl. 332 1468-1476 (2007)

13. Kannan, R: Some results on fixed points. Bull. Calcutta Math. Soc. 60, 71-76 (1968)

14. Karapınar, E: Some nonunique fixed point theorems of Ciric type on cone metric spaces. Abstr. Appl. Anal. 2010, Article ID 123094 (2010)

15. Kutbi, MA, Ahmad, J, Azam, A: On fixed points of $\alpha$ - $\psi$-contractive multi-valued mappings in cone metric spaces. Abstr. Appl. Anal. 2013, Article ID 313782 (2013)

16. Kutbi, MA, Azam, A, Ahmad, J, Di Bari, C: Some common coupled fixed point results for generalized contraction in complex-valued metric spaces. J. Appl. Math. 2013, Article ID 352927 (2013) 
17. Shah, MH, Simic, S, Hussain, N, Sretenovic, A, Radenovic, S: Common fixed points theorems for occasionally weakly compatible pairs on cone metric type spaces. J. Comput. Anal. Appl. 14, 290-297 (2012)

18. Rouzkard, F, Imdad, M: Some common fixed point theorems on complex valued metric spaces. Comput. Math. Appl. (2012). doi:10.1016/j.camwa.2012.02.063

19. Sintunavarat, W, Kumam, P: Generalized common fixed point theorems in complex valued metric spaces and applications. J. Inequal. Appl. 2012, Article ID 84 (2012)

20. Sintunavarat, W, Cho, YJ, Kumam, P: Urysohn integral equations approach by common fixed points in complex valued metric spaces. Adv. Differ. Equ. 2013, Article ID 49 (2013)

21. Sitthikul, K, Saejung, S: Some fixed point theorems in complex valued metric spaces. Fixed Point Theory Appl. 2012, Article ID 189 (2012)

22. Klin-eam, C, Suanoom, C: Some common fixed point theorems for generalized-contractive-type mappings on complex valued metric spaces. Abstr. Appl. Anal. 2013, Article ID 604215 (2013). doi:10.1155/2013/604215

23. Khan, MS: A fixed point theorem for metric spaces. Rend. Ist. Mat. Univ. Trieste 8, 69-72 (1976)

10.1186/1029-242X-2013-578

Cite this article as: Azam et al.: Common fixed point theorems for multi-valued mappings in complex-valued metric spaces. Journal of Inequalities and Applications 2013, 2013:578

\section{Submit your manuscript to a SpringerOpen ${ }^{\circ}$ journal and benefit from:}

- Convenient online submission

Rigorous peer review

- Immediate publication on acceptance

- Open access: articles freely available online

- High visibility within the field

- Retaining the copyright to your article 